\title{
POLÍTICA, UNIVERSIDAD Y SOCIEDAD EN PUEBLA, EL ASCENSO DEL PARTIDO COMUNISTA MEXICANO EN LA UAP, 1970-1972
}

\author{
Jesús Márquez Carrillo ${ }^{1}$ \\ Centro de Estudios Universitarios \\ Facultad de Filosofía y Letras-BUAP \\ jesusm146@hotmail.com \\ Paz Diéguez Delgadillo ${ }^{2}$ \\ Centro de Estudios Universitarios \\ Facultad de Filosofía y Letras-BUAP \\ dieguezdelgadillo@yahoo.com.mx
}

Recepción: 30/05/2008

Evaluación 01/06-15/09/2008

Aceptación: 29/09/2008

Artículo de Reflexión

\section{RESUMEN}

En 1972, miembros del Partido Comunista Mexicano asumieron la dirección de la Universidad Autónoma de Puebla. El propósito del presente artículo es describir y analizar el proceso inmediato por el cual llegaron al poder, considerando los discursos políticos que les influyeron y el problema coyuntural de la masificación, más los vínculos de la Universidad con la movilización social y asimismo sus conflictos con los grupos locales de poder. Los materiales que le sirven de base son documentos de archivo, noticias hemerográficas y bibliografía.

Palabras Clave: Movimientos estudiantiles, política, poder regional, Partido Comunista Mexicano, Universidad Autónoma de Puebla.

\footnotetext{
${ }^{1}$ Doctor en Educación por la Universidad Autónoma de Aguascalientes (México). Ponente en foros nacionales e internacionales, conferenciante y colaborador de varios medios impresos, la radio y la televisión, es autor, entre otros

${ }^{2}$ Es estudiante del Doctorado en Educación en la Universidad Autónoma de Tlaxcala (2005 -2008), Maestra en Administración y Gestión de Instituciones Educativas, Ponente en varios foros nacionales e internacionales. Profesora investigadora de la Maestría en Educación Superior en el Centro de Estudios Universitarios de la Facultad de Filosofía y Letras de la Benemérita Universidad Autónoma de Puebla.
} 


\title{
POLITICS, UNIVERSITY AND SOCIETY IN PUEBLA: THE ASCENT OF MEXICAN COMMUNIST PARTY IN THE UAP, 1970-1972
}

\author{
Jesús Márquez Carrillo \\ Centro de Estudios Universitarios \\ Facultad de Filosofía y Letras-BUAP \\ jesusm146@hotmail.com \\ Paz Diéguez Delgadillo \\ Centro de Estudios Universitarios \\ Facultad de Filosofía y Letras-BUAP \\ dieguezdelgadillo@yahoo.com.mx
}

\begin{abstract}
In 1972, members of the Mexican Communist Party took over the leadership of Universidad Autónoma de Puebla. The purpose of this article is to both describe and analyze the process by which they immediately came to power, considering the political speech that influenced them and the cyclical problem of overcrowding, more links with the University of social mobilization and also its conflict with the Groups of local power. The materials that will serve as the reference are archival documents, library records and literature news.
\end{abstract}

Key Words: Student movements, Politics, Regional Power, Mexican Communist Party, Universidad Autónoma de Puebla.

\section{INTRODUCCIÓN}

Después del movimiento estudiantil y popular de 1968, la Educación Superior en nuestro país vivió diversos y significativos conflictos, que modificaron el hacer y quehacer de las universidades públicas. ${ }^{3}$ La Universidad Autónoma de Puebla no fue la excepción. ${ }^{4}$ En la década posterior a ese acontecimiento vivió

\footnotetext{
${ }^{3}$ BRUNNER, José Joaquín. (1990): Educación Superior en América Latina. Cambios y desafios. Santiago de Chile, Fondo de Cultura Económica, pp. 71-132; GUEVARA NIEBLA, Gilberto. (1981): Introducción: los múltiples rostros de la crisis universitaria, en La crisis de la educación superior en México. México, Nueva Imagen, pp. 11-21; DIDRIKSSON, Axel y HERRERA, Alma (coords). (2002): La transformación de la universidad mexicana. Diez, estudios de caso en transición. México, Editorial Porrúa, Universidad Autónoma de Zacatecas.
} 
un importante proceso de cambio, el cual hizo crisis a finales de los ochenta y dio pie a su modernización actual. Autores como Jesús Márquez Carrillo, Ricardo Moreno Botello, Adrián Acosta Silva, Carlos Ornelas, Wietse de Wries, Wil Pansters y Alfonso Vélez Pliego han documentado esta historia todavía reciente, con distintos enfoques y desde distintas perspectivas analíticas. ${ }^{5}$

Sin embargo, como está ausente una política institucional de la memoria y el cultivo de una conciencia histórica compartida, hoy, muchos universitarios en particular los que ostentan algún puesto de responsabilidad académica o administrativa- emiten juicios ligeros sobre el pasado inmediato de la Universidad, como si su historia no tuviese que ver con el presente y sus eventuales cambios. ${ }^{6}$ En cierto modo, reemplazan "el zigzagueo dramático del devenir social con un quieto panorama de leyendas convencionales". ${ }^{7}$ Baste mencionar imágenes e ideas que de tanto repetirlas se han vuelto patrimonio y parte de una

${ }^{4}$ Esta Casa de Estudios se encuentra en Puebla capital, una ciudad distante 129 kilómetros al Oriente de la ciudad de México, en la provincia geológica del Eje Neovolcánico, caracterizado por la presencia de altas cumbres y una sucesión de valles. Precisamente, la ciudad Puebla se ubica en un anchuroso valle, rodeada de campos fértiles. En 2007, con una población superior a los 1.5 millones de habitantes, concentraba el $85 \%$ de la actividad industrial de la entidad o provincia. Por su parte, la hoy Benemérita Universidad Autónoma de Puebla ocupa el quinto lugar entre las universidades públicas estatales de la República Mexicana, ofrece 61 licenciaturas y 59 postgrados. En 2007 tenía una población de 57,270 estudiantes. "Fundamento: Benemérita Universidad Autónoma de Puebla" en: http://www2.standardandpoors.com/portal/site/sp/es/la/page.article/ 2,1,7,0,1148448695112.html. Recuperada: 2/X/2008.

${ }^{5}$ MÁRQUEZ CARRILLO, Jesús. (1992): Cátedra en vilo. Apuntes y notas de bistoria universitaria poblana. Puebla, Centro de Estudios Universitarios-BUAP; MÁRQUEZ CARRILLO, Jesús (2008): "Los orígenes de la Universidad Democrática, Crítica y Popular", en AGÜERA IBÁÑEZ, Enrique (coord.), El 68 en Puebla. Memoria y encuentros. Puebla, Benemérita Universidad Autónoma de Puebla, pp. 75-86; ACOSTA SILVA, Adrián (2000): Estado, políticas y universidades en un periodo de transición. Análisis de tres experiencias institucionales en México. México, Fondo de Cultura EconómicaUniversidad de Guadalajara; VRIES, Wietse de, MORENO BOTELLO, Ricardo. (1996): "Historia de una crisis autónoma. La UAP de 1975 a 1990", en La mirada del Fénix. Puebla, Centro de Estudios Universitarios, pp. 129-166; VRIES, Wietse de (2001): El exorcismo de diablos y ángeles. Los efectos de las Politicas públicas sobre el trabajo académico. Aguascalientes, Universidad Autónoma de Aguascalientes; ORNELAS, Carlos. (1994): De la crisis a la reconstrucción: el cambio institucional en la BUAP. México, ANUIES; PANSTERS, Wil. (1998): Política y poder en Puebla. Formación y ocaso del cacicazgo avilacamachista, 1937-1987. México, Fondo de Cultura Económica; PANSTERS, Wil (coord). (1996): La mirada del Fénix. Universidad y sociedad en Puebla, 1880-1990. México. Centro de Estudios Universitarios-BUAP; VELEZ PLIEGO, Alfonso (1978): "La sucesión rectoral, las lecciones de la historia y las tareas actuales del movimiento universitario democrático", en Revista Crítica de la UAP. Puebla, Universidad Autónoma de Puebla, año I, núm. 1, pp. 41-96.

${ }^{6}$ El único esfuerzo notorio por rescatar y difundir la historia universitaria corresponde al Archivo Histórico, a través de su gaceta Tiempo Universitario y su colección de libros que, en los dos sexenios anteriores, financió casi en su totalidad el gobierno del Estado. Por eso, este afán no puede considerarse una política universitaria; es, mas bien, una medida aislada.

${ }^{7}$ INGENIEROS, José. (1936): Las Fuerzas morales, Santiago de Chile, Ediciones Ercilla, p. 102. 
sensibilidad común, cuyo propósito es justificar, más que comprender, las transformaciones de la Universidad en las últimas décadas. Así-al margen de cualesquier consideración sobre el entramado social e histórico en el que se inserta nuestra Casa de Estudios-, se habla de la precariedad institucional, la inestabilidad política y el desprestigio de la UAP, durante la gestación, desarrollo y crisis del denominado proyecto de Reforma Universitaria en su tercera fase, que corresponde a la Universidad, Democrática, Crítica y Popular (1972-1989); y es precisamente, debido a esta situación -se dice- que la Universidad tuvo un viraje radical en los noventa y consiguió elevar su calidad bajo nuevas exigencias sociales, lo que significó una novedad y una aventura sin precedentes: su arribo al siglo XXI como institución moderna. ${ }^{8}$ Pero igual, en los primeros tiempos de la Reforma Universitaria, sobre todo en su fase liberal (1961-1965) se invocaba el pasado más próximo para subrayar el profundo atraso académico de la Universidad y la urgencia de transformarla, según las exigencias de una sociedad en pos de su modernización. ${ }^{9}$ Entonces se hacía notar su escasa o nula capacidad para la generación de nuevos conocimientos a través de la investigación; su falta de personal docente profesionalizado; la ausencia de una administración eficaz de los asuntos universitarios, y su desatención a las expectativas y motivaciones de las nuevas generaciones. ${ }^{10}$

Sin dejar de reconocer que muchas críticas son válidas y que aun deben profundizarse, esta manera de percibir a la Universidad actual no contribuye a comprender sociológica e históricamente la dimensión de las transformaciones

\footnotetext{
${ }^{8}$ ORNELAS, Carlos. Op cit., pp. 18-19. Este autor sólo se refiere al periodo de 1987 1990 , pero sus observaciones suelen ser extrapoladas al proyecto en su conjunto. Para un balance sobre los cambios de la BUAP en los noventa, VRIES, Wietese 2002, pp. 4972 .

${ }^{9}$ El desarrollo de una institución no es homogéneo, conviven lo tradicional y lo moderno. Hoy pocos universitarios saben, por ejemplo, que en 1964 un profesor de la escuela de Físico-matemáticas, el doctor Leopoldo García Colín, obtuvo el Premio Nacional de Ciencias y que antes de la "fiebre por los doctorados" y la certificación, en esa dependencia impartían clases un número significativo de doctores, ingenieros y físicos de renombre. Entre los doctores en física son de citarse a Leopoldo García Colín, Virgilio Beltrán, Eugenio Ley Koo y Fernando Chaos. En 1964, la escuela tenía de profesores visitantes al doctor Jens G. Zorn, de la Universidad de Michigan y al físico Daniel Pinkel, de la National Bureau of Standars, de Washington, D. C. Vid. LARA Y PARRA, Manuel, (2002): La lucha universitaria en Puebla, 1923-1965. Edición y notas de MÁRQUEZ CARRILLO, Jesús. Puebla, Gobierno del Estado de Puebla, Benemérita Universidad Autónoma de Puebla, pp. 166-168.

${ }^{10}$ BRUNNER, José Joaquín. Op. cit, p. 56. Sobre el ideario de la reforma Universitaria en Puebla, vid. "Principales puntos del Movimiento estudiantil", en La Opinión. Diario de la mañana, 11 de junio de 1961, p. 1.
} 
ocurridas en las últimas décadas, pues, a través del juicio y la opinión fácil se condena a la desmemoria y al olvido una buena parte del pasado. ${ }^{11}$

Una asignatura pendiente en la historiografía mexicana es la historia de la relación de los partidos políticos con las universidades, pese a su importancia para comprender la formación de la élite política, su socialización y reclutamiento. ${ }^{12}$ En el caso de la Universidad Autónoma de Puebla, en 1972, miembros del Partido Comunista Mexicano llegaron a dirigir sus destinos. Ello fue posible, debido, entre otras cosas, a: las pugnas internas de los empresarios con respecto al desarrollo económico y político de la entidad; el papel de distintas organizaciones políticas en la movilización social del campo y el medio urbano y, sobre todo, a la política de Luis Echeverría con respecto a las Universidades. ${ }^{13}$ En este contexto, los militantes de izquierda -no sólo los del Partido Comunistapropusieron un conjunto de medidas para transformar la educación superior. En 1975 la Universidad Autónoma de Puebla puso en marcha su proyecto de Universidad Democrática, Crítica Popular. Entre 1964-1973, el apoyo de la Universidad poblana a las luchas de los trabajadores y pequeños empresarios produjo dobles beneficios. Algunos grupos de los grandes empresarios y del gobierno federal utilizaron el auge de los conflictos sociales para combatir y desplazar a sus aliados o, al menos, contraer su influencia. Al mismo tiempo, la izquierda -y en especial el Partido Comunista Mexicano- obtuvo el control de la UAP. ${ }^{14}$

El propósito del presente artículo es describir y analizar el proceso inmediato por el cual llegaron al poder los miembros del Partido Comunista, considerando los discursos políticos que les influyeron y el problema coyuntural

${ }^{11}$ Si el olvido social puede definirse como la imposibilidad de evocar o expresar "acontecimientos significativos que en algún momento ocuparon un sitio en la vida del grupo, sociedad o colectividad, pero cuya comunicación se ve bloqueada o prohibida por entidades supra grupales, como el poder o la dinámica social, que pretenden silenciar o relegar esos sucesos significativos de una sociedad, por la razón de que se pretende imponer una sola visión sobre el pasado vivido y experimentado por esa colectividad o porque no interesan para el modelo social que impera en ese momento", el olvido por el que transita la Benemérita Universidad Autónoma de Puebla -y en general las instituciones públicas de educación superior del país- puede ser peligroso aun para las transformaciones que ella impulsa. Cita de Mendoza García, 2005, pp. 10-11.

${ }^{12}$ Durante "varias generaciones, apunta Roderic Camp, profesores y estudiantes han usado a otros estudiantes como una base para el desarrollo de las amistades necesarias para la adquisición del poder político en México". CAMP, Roderic A (1988): Los intelectuales y el Estado en el México del siglo XX, México, Fondo de Cultura Económica, p. 35.

${ }^{13}$ GÓMEZ JARA, Francisco. (1981): El movimiento campesino. México, Secretaría de la Reforma Agraria-Centro de Estudios del Agrarismo en México. pp. 219-228; THERÁN, Marta. (1980): "El levantamiento de los campesinos gasquistas", en Cuadernos Agrarios. México, Editorial Macehual, Año V, No. 10-11. pp. 115-130; VÉLEZ PLIEGO, Alfonso. (1978): "La sucesión rectoral, las lecciones de la historia y las tareas actuales del movimiento universitario democrático", en Crítica. Revista de la UAP. Año I, No. 1. pp. 17-72.

${ }^{14}$ La sucesión rectoral y crisis de la izquierda... p.8. 
de la masificación, más los vínculos de la Universidad con la movilización social y asimismo sus conflictos con los grupos locales de poder. Los materiales que le sirven de base son entrevistas, documentos de archivo, artículos, noticias hemerográficas y bibliografía. Para la tarea de elucidar, interpretar y comprender el fluir de los acontecimientos, se procedió al registro puntual de los datos y a su lectura crítica. También se confrontaron varias versiones. La metodología que se utilizó fue la de historia político-social.

\section{Política y discurso}

El discurso político y social es un sistema que tiene un efecto estructurante, pero no determinante, sobre la conducta de los individuos, las comunidades y los grupos sociales; es no sólo lo que enuncia la acción, sino también, por efecto de retorno, lo que la produce, pero no de manera arbitraria, sino dentro de ciertos límites sociales de interpretación. Haciendo un parangón con la historia social rusa pre-revolucionaria (ca. 1895-1917) los militantes de la izquierda universitaria reivindicaron hacia afuera de la institución su papel activo en las luchas populares, pues, a decir de Lenin, sólo el apoyo del pueblo -y principalmente el apoyo de los obreros- puede asegurar el éxito, y para conseguir tal apoyo se debería luchar "no solamente por la libertad académica (estudiantil) sino por la libertad de todo elpueblo, por la libertad política". ${ }^{15}$ Justamente el lema de luchar mientras se estudia enarbolado por la Juventud Comunista, aspiraba a concretar este horizonte. ${ }^{16}$

Ahora bien, con base en el análisis marxista-leninista era evidente que la diferencia de intereses de clase se expresaba también entre los estudiantes. ${ }^{17}$ Con miras a fortalecer una nueva concepción del mundo, el ingreso a la Universidad de alumnos pobres, hijos de obreros y campesinos, resultaba por partida doble fundamental. Si por un lado sólo la enseñanza gratuita y obligatoria "puede sacar al pueblo, aunque sólo sea en parte de su ignorancia actual", en otro plano, los estudiantes se concebían a sí mismos como el eje concientizador de las masas, "la vanguardia de la democracia revolucionaria". ${ }^{18}$ Desde esta perspectiva, estudiantes y luchadores de izquierda concibieron a la universidad poblana como el vínculo necesario de los movimientos sociales y el sitio privilegiado desde donde la teoría podía incidir en la praxis. Por eso algunas de sus propuestas fueron:

${ }^{15}$ LENIN, V. I. (1973): La autonomía universitaria y el papel revolucionario del movimiento estudiantil. p. 65

${ }^{16}$ MARTÍNEZ NATERAS, Arturo. (1972): Ser y función social del Estudiante. Culiacán, Universidad Autónoma de Sinaloa. p. 86.

${ }^{17}$ LENIN. (1973): Op.cit. pp. 52, 53, 55; MARTÍNEZ, Nateras. (1972): Op. Cit. pp. 51-52.

${ }^{18}$ LENIN, V.I. (1963): A los pobres del campo. Los objetivos de los socialdemócratas explicados a los campesinos, en: La alianza de la clase obrera y del campesinado. pp. 95-168. La Habana, Editora Política, pp. 95-168. 
1. Constituir brigadas políticas para -frente al control oficial- canalizar el descontento de obreros y campesinos hacia formas independientes de organización partidarias o, en todo caso, combativas; $y$, asimismo difundir entre el pueblo las luchas de los trabajadores urbanos y rurales, como parte de su tarea concientizadora.

2. Hacer de la Máxima Casa de Estudios un sitio para la organización y defensa de los movimientos obrero, campesino y popular, contra la intolerancia y la represión de los patrones, el gobierno y otras autoridades. Se trata -decíande que el descontento encuentre un espacio para expresarse, pero también de que los universitarios comprometidos en la lucha de clases, asesoren las legítimas demandas de quienes las enarbolan. Y, por último,

3. Crear y difundir una expresión cultural, donde el mensaje carezca de mediaciones y donde la extensión universitaria, además de ofrecer al pueblo los saberes adquiridos, le ofrezca el cuestionamiento de su realidad. ${ }^{19}$

Desde luego, las condiciones en que nace este horizonte discursivo se fueron conformando durante muchos años, pero para su emergencia en el ámbito regional se dieron cita distintos procesos sociales y políticos. Finalmente la metodología empleada giro en torno a la historia política.

\section{Política y Masificación}

Uno de los primeros retos que los grupos de izquierda y liberales tuvieron que enfrentar en los primeros años de la séptima década, fue el acceso masivo de estudiantes a la Universidad, puesto que ello implicaba resolver el problema de cómo - dada la precariedad del subsidio-, dar cabida a los mismos sin disminuir los ya mermados niveles académicos. La respuesta no fue aséptica y necesariamente se inscribió en la trama de lo social. De esta suerte surgieron la Preparatoria Popular "Emiliano Zapata" y estalló el conflicto de la Escuela de Medicina.

Desde fines de 1969, las autoridades universitarias ante la imposibilidad de absorber a todos los estudiantes que pretendían ingresar a las escuelas de preparatoria y de Medicina, acordaron restringir el ingreso a la misma mediante un examen selectivo. Era, argumentaban, bastante baja la preparación y urgía levantarla homogeneizando desde el principio los conocimientos del alumno. Luego del examen, los rechazados que aspiraban a la Preparatoria buscaron el apoyo de los Comités de Lucha, surgidos en 1968 y en especial de los grupos

\footnotetext{
${ }^{19}$ Para una visión más precisa, los documentos de Rivera Terrazas, 1978 y 1980.
} 
de izquierda y liberales, configurados desde los años cincuenta, en oposición a los grupos de derecha, que por esa época fundaron del Frente Universitario Anticomunista. Todos ellos propusieron la apertura de una nueva Preparatoria y la ampliación del número de grupos en el primer año de la Escuela de Medicina. ${ }^{20}$

En tanto, la derecha radical poblana percibió el peligro, lanzándose en contra de tales propuestas desde las escuelas de Administración de Empresas, Ingeniería Civil, Ingeniería Química, Arquitectura y Medicina. ${ }^{21}$ Mas, pese al clima adverso, la escuela Preparatoria Popular abrió sus puertas el 5 de enero de 1970 con 830 alumnos. Un mes más tarde, el 10 de febrero, el Consejo Universitario la legalizó. ${ }^{22}$

Con respecto a la Escuela de Medicina, hasta 1968 tenía 1200 alumnos pero en 1969 fueron admitidos sólo en el primer año 900, mientras que su presupuesto se redujo en un $4.2 \% .{ }^{23}$ En vista de las limitaciones presupuestarias y la falta de espacio físico, la Academia de Maestros acordó en noviembre de 1969 limitar el ingreso a 350 estudiantes, quienes serían seleccionados conforme a las notas de un examen. Se trataba de responder a los problemas de una escuela en crecimiento y de preservar entre los maestros las orientaciones hipocráticas sobre la relación docente-enfermo-alumno. Abrir más grupos repercutía, argumentaron los maestros, en un bajo aprovechamiento y la pérdida de la enseñanza personalizada. ${ }^{24}$

Los aspirantes asistieron a un curso propedéutico. El día del examen se presentaron 1003 alumnos, 356 de la Escuela Preparatoria "Benito Juárez" y el resto de escuelas particulares, oficiales e incorporadas; pero sólo 79 obtuvieron hasta el mínimo aceptable de seis; de éstos, 46 provenían de la preparatoria "Benito Juárez". Aplicando un promedio de 5, la cifra subió a 218. ${ }^{25}$ Pero los rechazados, con el apoyo de los Comités de Lucha y los grupos políticos liberales y de izquierda, iniciaron un movimiento exigiendo su ingreso. ${ }^{26}$

$\mathrm{Al}$ mismo tiempo, la Academia de Maestros y el Consejo Técnico de la Escuela se pronunciaron por suspender las clases si el Consejo Universitario decidía hacer caso omiso de su determinación de elevar el nivel académico. ${ }^{27} \mathrm{El}$

\footnotetext{
${ }^{20}$ La comisión organizadora estuvo integrada por Luis Ortega Morales, Marco A. Sánchez Daza, Alberto Montero, Silvestre Angoa y Alfredo Romero Palma.

${ }^{21}$ VÉLEZ PLIEGO, Alfonso. (1978): "La sucesión rectoral, las lesiones de la historia y las tareas actuales del movimiento universitario democrático" en: Crítica. Revista de la UAP. Año I, No. 1, oct.-dic., p. 72

22 "Legalizan la educación de 800 alumnos de bachillerato" El Sol de Puebla 11/II/ 1970

23 "Falta de vocación, problema de la UAP" Novedades 11/II/1970.

24 "Amenaza de paro a la U.A.P”. Novedades. 4/II/1970.

${ }^{25}$ Desplegado del Consejo Técnico. El Sol de Puebla 15/II1970.

26 "Amenaza de paro a la U.A.P." Novedades. 4/II/1970.

27 “Amenaza de paro a la U.A.P." Novedades. 4/II/1970; Desplegado del Consejo Técnico.

El Sol de Puebla 15/II1970.
} 
11 de febrero la Máxima Autoridad de la UAP, aceptó que ingresaran otros 139 estudiantes, puesto que existía el pase automático y que en un principio se habían ofrecido 350 lugares, y apenas estaban cubiertos $211 .{ }^{28} \mathrm{La}$ Academia de Maestros acordó (13/II/1970), en plena rebeldía y enfrentamiento con el Consejo Universitario, irse al paro porque con aceptar más alumnos el Consejo Universitario sólo demuestra "su desconocimiento de las altas funciones que la Escuela de Medicina tiene y de su obligación ante la sociedad poblana y ante la nación de preparar profesionistas capaces que llenen la función de conservar y restaurar la salud de los mexicanos", y una profesión como ésta no puede realizarse con alumnos impreparados. ${ }^{29}$ Por último, sin ningún acuerdo entre las partes, la Academia se pronuncia, el 3 de abril, por suspender el paro para no perjudicar más a los buenos estudiantes", sin que ello implique ceder a los acuerdos del Consejo Universitario. ${ }^{30}$ Un enfrentamiento inclina la balanza a favor de los rechazados. ${ }^{31} \mathrm{El} 8$ de abril se reúne el Consejo Universitario y decide ratificar sus acuerdos del 11 de febrero y suspender a los estudiantes responsables directos de la agresión, así como al instigador de los hechos. ${ }^{32}$

Al día siguiente, en la Escuela de Medicina, una asamblea de estudiantes y jefes de grupo y otra de maestros, rechazan los acuerdos del Consejo porque no proceden. El conflicto tiende a crecer. Estudiantes de Administración de Empresas se van al paro en apoyo a Medicina y las escuelas de Ciencias Económico Administrativas (Contaduría), Arquitectura, Ingeniería Civil e Ingeniería Química declaran que ofrecen su apoyo moral al Consejo Técnico y a la Academia de Maestros. $^{33}$

La lógica opositora era sumarse a las exigencias de la Academia de Maestros para presionar al gobierno y que éste tomara cartas en el asunto. Estas sin embargo, poco tenían que ver propiamente con la escuela de Medicina. Se trataba para las fuerzas de derecha de volver a controlar la Universidad a partir de aquellos puntos más frágiles y problemáticos como eran las preparatorias. Por eso, la Sociedad Médica de Puebla propuso al gobierno del Estado separar de la Universidad a las escuelas preparatorias para que fuesen a depender de la Secretaría de Educación Pública: "se elevara la calidad académica de los estudios preparatorianos y se evitara que los estudiantes sean usados por delincuentes a sueldo", concluía la solicitud..$^{34}$

\footnotetext{
28 “Aprobó el Consejo de la U.A.P. El ingreso de 139 jóvenes a Medicina”. El Sol de Puebla. 12/II/1970.

${ }^{29}$ Desplegado de la Academia de Maestros. El Sol de Puebla 15/II/1970.

${ }^{30}$ Desplegado de la Academia de Maestros. El Sol de Puebla 7/IV/1970.

${ }^{31}$ Desplegado de la Sociedad Médica de Puebla. La Voz de Puebla 15/IV/1970.

32 "Expulsión en la Universidad". El Heraldo 9/IV/1970; "Hoy" La Opinión 9/IV/ 1970.

33 "En la Escuela de Medicina rechazan acuerdos del Consejo Universitario" La Voz de Puebla 9/IV/1970.

${ }^{34}$ Desplegado de la Sociedad Médica de Puebla. La Voz de Puebla 15/IV/1970.
} 
En los meses que siguieron se extendió la lucha. Por fin, el Consejo Universitario acordó nombrar (9/VI/1970) una Comisión Coordinadora Interina. Los médicos maestros persistieron en sus demandas: solo 38 de los 106 apoyaron el Consejo Universitario; el resto nombró director de la Escuela al doctor Manuel Santillana, quien durante su rectorado (1956-1959) había favorecido el auge de las organizaciones católicas paraeclesiales. ${ }^{35}$

A su vez, los Comités de Lucha para hacer valer los acuerdos del Consejo Universitario y dar posesión a los coordinadores nombrados por él mismo, tomaron las instalaciones de la Escuela el 12 de junio, pero el día 15, a las cuatro de la mañana, un grupo de 100 estudiantes se apoderó del edificio. Ese día se llevó a cabo un duro enfrentamiento, cuyo saldo fue de un estudiante muerto y alrededor de 50 lesionados, 9 de ellos con bala. ${ }^{36}$ Por la gravedad de los hechos, la Comisión Coordinadora, de común acuerdo con la Junta Administrativa, suspendió las actividades en la escuela y el Consejo Universitario acordó expulsar a los principales agresores. Poco más tarde 25 maestros de la Academia renunciaron en bloque, con la idea de fundar otra escuela. ${ }^{37} \mathrm{Un}$ registro de la época permite decir que más del $60 \%$ de los catedráticos siguió el mismo camino, aún cuando carecieran de idéntico propósito. ${ }^{38}$ En estas condiciones la escuela re-abrió sus puertas el 13 de julio..$^{39} \mathrm{La}$ autoridad del Consejo Universitario se había impuesto, pero con un costo bastante alto; al ingreso masivo de estudiantes no pudo corresponderle una experimentada Academia.

\section{Política, Reforma Universitaria y Movilización Social}

Durante los meses que siguieron a la reapertura de la escuela de Medicina, la polarización en la Universidad se fue haciendo aún más evidente. A principios de 1971, el 9 de febrero, precedido de una activa lucha contra el alza de precios en la que participan -a través del Frente Autodefensa del Pueblo- profesores y alumnos de la Preparatoria Popular con obreros, campesinos y vendedores ambulantes, los Comités de Lucha toman el edificio carolino y se pronuncian por profundizar el movimiento de Reforma Universitaria, sobre la base de que siendo la Universidad parte del Pueblo, su causa primaria y su fin único, la educación debe responder a los siguientes fines: “a) Educación para la liberación;

\footnotetext{
35 "Los maestros nombran director al Doctor Manuel Santillana" La Opinión 10/VI/ 1970; "Rechazan alumnos y maestros a la Comisión Coordinadora". La Opinión 11/VI/ 1970. "Renunció el Dr. Arvea a la Academia de Maestros de Medicina" Novedades 13/ VI/1970.

${ }^{36}$ Cfr. La prensa local de los días 16 y 17 de junio de 1970.

37 "Renuncian 25 maestros en Medicina" Novedades 25/VI/1970.

${ }^{38}$ GAMBOA OJEDA, Ivanhoe. (1982): Historia de la escuela de medicina de la UAP.

Puebla, edición del autor. op. p. 29.

${ }^{39}$ Cfr. La prensa local de los días 14, 15 y 16
} 
b) Educación dirigida a promover el cambio de las estructuras generales de la sociedad; c) Educación inscrita en la hora latinoamericana y en las necesidades concretas nacionales". 40

Urge, argumentaron, una filosofía de la Universidad "objetiva, científica y social, que tome en cuenta la realidad en que está inscrita y cuya promoción (...) en su razón de ser. Una Universidad sin relación estrecha con la realidad social... una Universidad no popular, es inconcebible. ${ }^{41}$ Con respecto a sus demandas inmediatas piden: la renuncia de la Junta Administrativa; el cese de funcionarios ladrones y corruptos; la paridad estudiantil en el Consejo Universitario, una Ley Orgánica que beneficie al estudiantado y al Pueblo; la formación de una gran asamblea de planificación universitaria; el aumento de subsidio; una auditoría general y externa, haciéndose acompañar de alumnos y maestros; y, el conocimiento público del patrimonio universitario actual. ${ }^{42}$

La respuesta de la derecha no se hace esperar. Si bien habían desaparecido el FUA y el MURO, las organizaciones de derecha que se enfrentaron a la modernización de la Universidad una década antes, son ahora los grupos Náhuatl y Juventud Nueva quienes asumen la ofensiva, a través de volantes. ${ }^{43} \mathrm{El} 10 \mathrm{de}$ febrero el Consejo Universitario suprime la preparatoria popular "Emiliano Zapata” y cinco días más tarde la Junta Administrativa de la Universidad sustituye a la Comisión Coordinadora de la Escuela Preparatoria "Benito Juárez" por el Q.F.B. José María Cordero Bernal (1931-). ${ }^{44}$ Por su parte el Gobierno del Estado también se suma a la ofensiva de la derecha, que mantiene sus reales en las escuelas de Arquitectura, Administración de Empresas e Ingeniería Civil, con cuyo apoyo nace el llamado Bloque de Ciudad Universitaria. En estas condiciones, el movimiento de Reforma resiste, pero recurre para consolidarse al apoyo del Ejecutivo Federal. ${ }^{45}$ Echeverría está interesado en reducir la influencia de la derecha poblana que no ve con buenos ojos sus pronunciamientos sobre Chile y el

\footnotetext{
${ }^{40}$ A raíz de este movimiento fueron detenidos los maestros Erika Treviño, Jorge Sánchez Zacarías, Luis Ortega Morales y Jorge Méndez Spíndola. Cfr. "Detienen a Profesores" La Opinión 28/I/1971; "La Universidad dice que el mitin de ayer no fue suyo" El Sol de Puebla 20/I/1971. Sobre estas demandas, "Documento que sentó las bases del movimiento de Reforma Universitaria”, en Cuadernos de debate, Puebla, UAP Nos.

${ }^{41}$ Idem.

42 "En el Frente universitario" El Sol de Puebla 15/II/1971.

${ }^{43}$ RIUS FACIUS, Antonio.(1980): ¡Excomulgado! Trayectoria y pensamiento del Pbro. Dr. Joaquín Sáenz Arriaga. México, Costa - Amic Eds., p. 94; ROBLEDO DE ESTRADA, Elsa. (1981): "La ultraderecha” en México", en Contenido, No 217, p. 37; Proceso Núm. 36, 11/VII/1977, pp. 10-16; Manuel Buendía “ ‘. . . ?” El Día 27/IX/1971; ZÚÑIGA, Francisco. "Puebla, once años de violencia", en Revista de Revistas. Núm. 12, 18/VIII/ 1972, pp. 3-9, 1972 pp. 3-9; VÉLEZ PLIEGO, Alfonso (1978): “Cronología” en Dialectica. Puebla, Universidad Autónoma de Puebla, p.10.

${ }^{44} V$ id. La prensa local del 16 al 20 de febrero.

${ }^{45}$ Aprovechando una visita que hiciera Echeverría a Atencingo, una comisión del movimiento se entrevista con él el 17 de febrero. Vélez Pliego. Cronología p.10
} 
Tercer Mundo; por eso establece con los reformadores universitarios una alianza táctica. Así, en medio de la zozobra cotidiana y de tremebundas felpas, se desenvuelve la lucha por el control del Consejo Universitario. Gracias a una alianza entre los principales grupos políticos-el del ingeniero Luis Rivera Terrazas, del PCM y el surgido en 1964, el de los liberales-, al clima de violencia que se ejerce en contra de la indefensa población escolar y al activismo de los Comités de Lucha, las fuerzas llamadas democratizadoras obtienen mayoría. ${ }^{46}$ El día que toma posesión el nuevo Consejo (31/III/1971) la asamblea concluye en tremendo enfrentamiento. ${ }^{47}$ Desde entonces, las acciones pandilleras se incrementan, a pesar de que el Consejo Universitario no escatima esfuerzos para evitarlas. ${ }^{48}$

Durante julio y agosto se desencadena otra ola represiva más intensa, auspiciada por los empresarios, la jerarquía eclesiástica y el gobierno. En uno de los enfrentamientos muere asesinado el estudiante Marco Antonio Márquez. ${ }^{49}$ El Consejo Universitario decide poner fin al derramamiento de sangre, expulsando al grupo responsable. ${ }^{50}$ El gobierno formalmente es imparcial, pero ofrece todo su apoyo al Bloque de Ciudad Universitaria.

\section{Política y Grupos de Poder}

La agudización del conflicto universitario provoca la renuncia del último miembro de la Junta Administrativa, el nombramiento de un nuevo rector y su caída. Entonces, el Consejo Universitario elige al licenciado Martín Carvajal Caro. Éste a pesar de sus vínculos con el gobernador, adopta una "actitud de acercamiento y colaboración con el movimiento democrático universitario y particularmente con el Grupo del $64 .^{51}$

Mientras tanto, en el PRI está en juego la elección del candidato a la presidencia municipal, y la fuerte campaña de la derecha contra la BUAP tiene aquí también su última palabra, sobre todo al resultar electo para el cargo, el doctor Gonzalo Bautista -líder en ese partido de la oposición más conservadora-,

\footnotetext{
${ }^{46} \mathrm{El}$ grupo del ingeniero Terrazas se había ido configurando en los cincuenta; el grupo del 64, encabezado por Juan José Barrientos y Nicandro Juárez, tenía sus orígenes en el movimiento popular estudiantil de 1964 contra Nava Castillo. Era liberal a la usanza mexicana.

${ }^{47}$ Cfr. La prensa Local de los primeros días de Abril.

${ }^{48}$ En no menos de 10 ocasiones, dirá el Consejo Universitario, el 19 de agosto de 1971, se suplicó a las autoridades estatales su intervención sin resultado alguno. AHU Consejo

Universitario. Lic. Martín Carvajal Caro A-J 1/2 Exp. 1.

${ }^{49}$ VÉLEZ PLIEGO, Alfonso. ( 1978): Op.cit. p. 75.

${ }^{50}$ AHU Consejo Universitario. Lic. Martín Carvajal Caro A-J 1/ 2 Exp. 1.

${ }^{51}$ VÉLEZ PLIEGO, Alfonso. (1978): Op.cit. p. 75.
} 
quien el 15 de febrero de 1972 asume la presidencia del Ayuntamiento. ${ }^{52}$ Así en contra de la política enunciada por Echeverría pareciera que se repite una nota común al menos desde Calles: el fortalecimiento de tendencias regionales siempre y cuando se muevan en sus estrictos marcos y no afecten en políticas del Ejecutivo Federal; de ocurrir lo contrario, este tiene en sus manos varios recursos para oponerse..$^{53}$ Así las cosas, las tensiones entre la Universidad y el gobierno del estado se suceden vertiginosamente, y el gobernador renuncia "por motivos de salud" en los primeros días de abril. Las fuerzas derechistas logran colocar en ese puesto a Gonzalo Bautista. ${ }^{54}$ Entonces, la represión a las personas y los movimientos sociales entra galopante, sobre la base de un discurso articulado en torno a los conceptos de la Ley y Orden. Frente al auge contestatario de los trabajadores urbanos y rurales y el movimiento de reforma universitaria, una ley autoriza el arresto inconmutable de 36 horas para cualquier individuo que parezca sospechoso. ${ }^{55}$

Ciertamente, se trata de contener el descontento social. Desde la segunda mitad de los sesenta el campo poblano es un polvorín que estalla por diversas vías, así contra el cacicazgo y la imposición política como por reivindicaciones agrarias. Varios ayuntamientos fueron depuestos u obligados a ceder debido a las acciones populares: Huehuetlán (1969) e Izúcar de Matamoros (1970), son los casos más notorios. Asimismo, la lucha por la tierra crece en 1970 y 1971. En abril de 1972 confluyen 72 pueblos en una gran marcha hacia la ciudad de México demandando la derogación del derecho de amparo en materia agraria, el reparto de latifundios en Puebla y Tlaxcala y la reducción de la pequeña propiedad a 20 hectáreas, pero la caminata es frenada en Llano Grande, México por dos compañías del ejército. Esto, desde luego, no calma la efervescencia; en los meses que siguen hay una grande oleada de invasiones. ${ }^{56}$

52 PANSTERS, Wil. (1990): Las élites políticas, Ms. p. 31.

${ }^{53}$ La idea consagrada por la Carta Magna de 1917, según la cual la República es una federación de estados libres y soberanos, oculta la dependencia efectiva que guardan las entidades con el gobierno federal y los gobernadores con el presidente. En realidad, esta tiene características políticas, militares y económicas, pues mediante distintos recursos jurídicos- políticos los gobernadores pueden ser depuestos; asimismo están sometidos a un sistema de control central que se ejerce a través de las zonas militares y otros funcionarios y políticos de menor importancia que informan sobre aquello que puede afectar, desde su muy particular punto de vista, la marcha del país. Vid. GONZẢLEZ CASANOVA, Pablo. (1975): La democracia en México. México, Ediciones Era.

${ }^{54}$ Gonzalo Bautista Castillo, padre de Gonzalo Bautista O’Farril, concibió siempre, el menos desde 1929, que el gobierno y la Iglesia católica debían permanecer unidos, pero separados. Él y Gustavo Díaz Ordaz, se dice que fueron caballeros de Colón. Bautista O’Farril siendo presidente municipal, inauguró en la Ciudad de Puebla la Junta Nacional de los Caballeros de Colón. "Texmelucan está con el Gral. Ávila Camacho" Diario de Puebla 20/I/1936; Zamarripa, 1964; p.89; Manuel Buendía. Pensamiento y Acción, p. 35.

${ }^{55}$ PANTERS, Wil. (1990): Op. Cit. p. 22

${ }^{56}$ Para detalles sobre el movimiento campesino a nivel nacional, Bartra, 1980, p. 15-66.

La crónica de Puebla, en "Insurgencia campesina...", 1973 p. 7-15. 
En la ciudad de Puebla los trabajadores de Volksvagen acuerdan separarse (15/IV/1972) de la Federación de Trabajadores de Puebla; el movimiento sindical ferrocarrilero mantiene una fuerte lucha contra los líderes, charros. ${ }^{57}$ Los trabajadores del Sindicato de Trabajadores electricistas de la República Mexicana, ganan las calles en diciembre de 1971; manifestaciones de solidaridad con Vietnam son frecuentes.

Al principio la actitud de Gonzalo Bautista hacia la Universidad es en dos sentidos. Por un lado apoya al grupo del 64 para que extienda y consolide su influencia en detrimento del grupo que encabeza el ingeniero Luis Rivera Terrazas y los Comités de Lucha; por otro, estimula las campañas anticomunistas que los pequeños y los grandes empresarios, las clases medias y la jerarquía católica, promueven. Hay para ello sin duda, condiciones de recepción favorables entre la sociedad que, informada sobre la guerrilla urbana y rural, a través de la radio y televisión, ve en esos movimientos una amenaza a su idílica estabilidad y un refuerzo a su dogmática formación católica. ${ }^{58}$

El grupo del 64, en su afán por influir en el rumbo de la Universidad empieza a trabar alianzas con liberales "moderados" y hasta grupos derechistas. Así las cosas, el 8 de junio se reúne el Consejo Universitario para ver, entre otros puntos, la demanda impulsada por los Comités de Lucha de la Escuela de Medicina en el sentido de incorporar el Hospital Civil del Estado a esta Máxima Casa de Estudios. ${ }^{59}$ Aprovechando la presencia de los estudiantes, sorpresivamente el grupo del 64 propone que se nombre un rector definitivo.

Esa mañana los Comités de Lucha de varias escuelas se habían reunido para hacer un balance acerca del grupo 64 y el rector interino, acordando denunciar los vínculos de este grupo con el gobierno del Estado y sostener en la rectoría, incluso en las próximas elecciones, a Carvajal Caro, debido a su actitud

\footnotetext{
${ }^{57}$ VÉLEZ PLIEGO, Alfonso (1978): “Cronología” en Dialéctica. Puebla, Universidad Autónoma de Puebla, p.12

${ }^{58}$ Después de Tlatelolco, muchos activistas del movimiento revolucionario se convencieron de que el único camino para transformar el país era la toma de las armas. Así entre 1969 y 1970 se formaron varias organizaciones guerrilleras (F.A.R.P.,F.E.R..,F.U.Z., C-A-P., M.A.R. etc.). En este sentido, el asalto a bancos y comercios y el secuestro de millonarios y políticos se concibió como una medida para financiar el movimiento y "devolver al pueblo parte del dinero arrancado por sus explotadores y como medio para difundir sus comunicados". Estas acciones, sin embargo, produjeron un efecto contrario a la concientización: la prensa, la radio y la televisión sembraron el miedo. Sobre las guerrillas en México, López, 1974.

${ }^{59}$ Por lo menos desde 1954 catedráticos y alumnos habían propuesto la creación de un hospital -escuela. En 1961 poco antes de que estallara la lucha estudiantil. Arturo Santillana había dirigido un movimiento similar. Cfr. Julio Camarillo " Reorganización física y funcional de la Facultad de Medicina de Puebla". Revista de la Asociación de Exalumnos. Puebla, Año IV No. 7, marzo de 1955 p. 36-37. La prensa local del 12 al 26 de abril de 1961.
} 
mediadora ${ }^{60}$ Pero ante estos hechos, la única salida espontánea es el repliegue. Para no convalidar la victoria de dicho grupo, poco antes de las votaciones, los consejeros de los Comités de Lucha y del grupo Terracista, abandonan el recinto, mientras otros de igual filiación mantienen un enfrentamiento campal con los simpatizantes de las nuevas alianzas urdidas por el grupo del $64 .{ }^{61}$ Poco más tarde los Comités de Lucha impulsan la candidatura del ingeniero Luis Rivera Terrazas. Sin embargo difiere su postulación a favor del químico Sergio Flores, su cuñado.

La llegada de Sergio Flores (activo militante en el PCM desde 1964) a la Rectoría de la BUAP está inmersa en "una intempestiva imbricación y confluencia de todo un entramado de múltiples y abigarrados focos de tensión sociales" e implica el nacimiento institucional de un discurso comprometido con los explotados." "Jornadas -dirá Miguel Ángel Burgos, representante de los Comités de Lucha en el acto donde toma posesión el nuevo rector- duras, largas y sangrientas a lo largo de once años, hoy han llegado a dar resultado; la posibilidad de que la Universidad en su conjunto sirva a las causas del pueblo. (...) Hoy... hablan las voces de los oprimidos, de los explotados, de los parias y de los estudiantes revolucionarios "nos adjudicamos esa voz porque nuestra posición en la cátedra, en la manifestación, en la solidaridad, en una palabra, en la práctica, ha sido a favor de los explotados. De la clase obrera y de los campesinos". "Por todas esas luchas, por todos los caídos y los privados de la libertad, nuestra responsabilidad es más grande"; (...) aún falta mucho camino por recorrer, muchas luchas que dar y desgraciadamente mucha sangre que derramar, porque la primera etapa del camino no terminará hasta que se elimine la explotación del hombre por el hombre. ${ }^{63}$

\section{CONCLUSIONES}

La llegada de Sergio Flores provoca la reacción más violenta de la derecha y el gobierno estatal. Así empieza el ciclo que culmina en los hechos sangrientos del $1^{\circ}$ de mayo de 1973. Durante esos meses el gobernador dirige personalmente la represión y la violencia. Ha olvidado las mediaciones y traba férrea alianza con los grupos anti-reformistas, siendo su primer crimen político el asesinato de Joel Arriaga Navarro (20/VII/1072). Justo antes de su muerte los edificios del centro aparecieron tapizados de pasquines contra los nuevos funcionarios

\footnotetext{
${ }^{60}$ Entrevista Jesús Márquez/ Everardo Rivera Flores 19/XII/1986; Entrevista Jesús Márquez/Antonio Pérez 10/IV/1980.

${ }^{61} \mathrm{Y}$ es que apenas se enteran los Comités de Lucha de esta jugada, se dirigen de lugar en donde sesiona el consejo con la consigna de disolverlo.

${ }^{62}$ SOTELO MENDOZA, Humberto. (1980): "El movimiento universitario popular en Puebla (1973-1983)", en Crítica. Puebla. Revista de la Universidad Autónoma de Puebla. No. 19, p.10.

${ }^{63}$ Revista de la Universidad Autónoma de Puebla. Vol. 1 Núms 2,3 y 4, 1973 pp. 48, 52.
} 
de rectoría. Era un tenso clima que recordaba "al de los progons zaristas o las razzias fascistas", al decir de Aguilar Mora. ${ }^{64}$

En este clima, la organización de los grupos de izquierda tiene pocas posibilidades para manifestarse y sin embargo, el miércoles 26 de julio, después de una manifestación en contra de la violencia que se ejerce sobre la Universidad, se constituye el Frente Obrero, Estudiantil, Campesino, Popular. Participan en él los Comités de Lucha, el Sindicato de Trabajadores Electricistas de la República Mexicana, el movimiento sindical ferrocarrilero, el Sindicato de Volkswagen, la Confederación Campesina Independiente y 25 organizaciones populares. Su objetivo es ayudar en las investigaciones sobre la muerte de Joel Arriaga y protegerse mutuamente de la escalada represiva. ${ }^{65} \mathrm{El}$ movimiento universitario entra así en una nueva fase de confrontación.

La Universidad -en concreto el grupo de Luis Rivera Terrazas-consigue todo el apoyo interesado de Luis Echeverría. Sólo con este llega a consolidarse un proyecto político universitario que a partir de 1975 se llamará Universidad Democrática, Crítica y Popular. A su vez, con las luchas de la Universidad, el poder ejecutivo federal conseguirá extinguir el cacicazgo político regional, establecido en los años treinta del siglo pasado por el general Maximino Ávila Camacho. El ocaso del cacicazgo avilacamachista está íntimamente ligado a la historia de la Universidad.

\section{FUENTES Y BIBLIOHEMEROGRAFÍA}

Archivos

$\begin{array}{ll}\text { AHU } & \text { Archivo Histórico Universitario } \\ \text { ASGUAP } & \text { Archivo de la Secretaría General BUAP } \\ \text { PECB } & \text { Papeles Enrique Cabrera Barroso } \\ \text { Entrevistas } & \end{array}$

Antonio Pérez/Jesús Márquez. Puebla, Puebla, 10/IV/1980.

Everardo Rivera Flores/Jesús Márquez. Puebla, Puebla, 19/XII/1986

Horacio Labastida Muñoz/Jesús Márquez. Ciudad de México, 16/III/1995

Manuel Lara y Parra/Jesús Márquez. Puebla, Puebla, 18/IV/1985.

Urbano Deloya Rodríguez/Jesús Márquez. Puebla, Puebla. 21/IX/1996.

Hemerografía local y nacional

ElDía. México, D. F. 1971-1972.

El Heraldo. México, D. F. 1970-1972.

ElSol de Puebla. Puebla, Pue. 1970-1972.

La Cultura en México, Suplemento de Siempre!, México, D. F. 1972.

La Opinión. Diario de la mañana. Puebla, Pue. 1961, 1970-1972.

\footnotetext{
${ }^{64}$ AGUILAR MORA, Miguel. (1972): Puebla a la hora del crimen político, en La Cultura en México, Suplemento de Siempre!, Núm. 549, 16/VIII/1972. p. VII.

${ }^{65}$ El Frente Obrero Estudiantil campesino popular se constituyó y ayudará en las investigaciones sobre la muerte de Joel Arriaga. En Atisbo 28/VI/1972. p. 1.
} 
La Voz de Puebla. Puebla, Pue. 1970-1972.

Novedades. México, D. F. 1970-1972.

Proceso. México, D.F. 1977.

Revista de la Asociación de Exalumnos. Puebla, Pue. 1955-1956

Revista de la Universidad Autónoma de Puebla. Puebla, UAP, 1973

\section{SELECCIÓN BIBLIOGRÁFICA}

ACOSTA SILVA, Adrián. (2000): Estado, políticas y universidades en un periodo de transición. Análisis de tres experiencias institucionales en México. México, Fondo de Cultura Económica-Universidad de Guadalajara.

AGUILAR MORA, Miguel. (1972): "Puebla a la hora del crimen político", en La Cultura en México, Suplemento de Siempre!, Núm. 549, 16/VIII/1972.

BARTRA, Armando. (1980): “Crisis Agraria y movimiento campesino en los setentas" en Cuadernos Agrarios, México, Editorial Macehual. Año V, Nos. 10-11, diciembre de 1980.

BRUNNER, José Joaquín. (1990): Educación Superior en América Latina. Cambiosy desafios, Santiago de Chile, Fondo de Cultura Económica.

CABRERA, Enrique. Génesis Politica de la Reforma Universitaria, PECB. Ms.

CAMP, Roderic A. (1988): Los intelectuales y el Estado en el México del siglo XX, México, Fondo de Cultura Económica.

DÁVILA PERALTA, Nicolás. (2001): Las santas batallas. El anticomunismo en Puebla. BUAP, México.

DÍAZ BARRIGA, Ángel. (1999): “Contexto nacional y políticas públicas para la educación superior en México, 1950-1995”, en Universidad contemporánea. Política y gobierno. México, CESU-UNAM/Miguel Ángel Porrúa.

DIDRIKSSON, Axel y HERRERA, Alma (coords). (2002): La transformación de la universidad mexicana. Diez estudios de caso en transición. México, Editorial Porrúa, Universidad Autónoma de Zacatecas. 


\section{Documento demoledor.}

"Documento demoledor sobre las sociedades secretas católicas a las que combate la iglesia" Crucero Núm. 4, XII/1964.

¿En el nombre de Dios?

“En el nombre de Dios? La ultraderecha abierta y clandestina”. Proceso Núm. 36, 11/VII/1977.

ESPARZA SORIANO, Antonio. (2000): Origen evolución y futuro en la UAP, BUAP. México.

ESTRADA DE ROBLEDO, Elsa. (1981): “La ultraderecha” en México. Contenido, No. 217, junio de 1981.

GÓMEZ JARA, Francisco. (1981): El movimiento campesino. Méx. Secretaría de la Reforma Agraria-Centro de Estudios del Agrarismo en México.

GONZÁLEZ CASANOVA, Pablo. (1975): La democracia en México, México, Ediciones Era.

GUEVARA NIEBLA, Gilberto. (1988): La democracia en la calle. Crónica del movimiento estudiantil mexicano, México, Siglo XXI Editores.

(1981): “Introducción: los múltiples rostros de la crisis universitaria”, en La crisis de la educación superior en México. México, Nueva Imagen.

INGENIEROS, José. (1936): Las Fuerzas morales, Santiago de Chile, Ediciones Ercilla.

\section{Insurgencia campesina}

"Insurgencia campesina: notas y testimonios" en Revista de la Universidad Autónoma de Puebla, Puebla, UAP. Vol. I. Nos. 5-6. abril- mayo de 1973.

LACLAU, Ernesto. (1980): "La política como construcción de lo impensable”. Comunicación presentada al coloquio sobre Materialidades Discursivas, París, Universidad de París.

La sucesión rectoral

La sucesión rectoral y crisis de la izquierda. La UAP en 1981, Prólogo de Daniel CAZÉS, Puebla. UAP, 1983, 3, tomos.

LÓPEZ, Jaime. (1974): Diez años de guerrillas en México, 1964-1974. México, Editorial Posada. 
LENIN, V.I. (1963): “A los pobres del campo. Los objetivos de los socialdemócratas explicados a los campesinos", en La alianza de la clase obrera y del campesinado. La Habana, Editora Política, 1963.

(1973): L a autonomia universitaria y elpapel revolucionario del movimiento estudiantil. México, Ediciones de Cultura Popular.

(s.f.): “¿Qué hacer? Problemas candentes de nuestro movimiento”, en Obras Escogidas, Moscú, Editorial Progreso, t.I.

MÁRQUEZ CARRILLO, Jesús. (1992): Cátedra en vilo. Apuntes y notas de historia universitaria poblana. Puebla, Centro de Estudios Universitarios-BUAP.

MÁRQUEZ CARRILLO, Jesús. (2008): “Los orígenes de la Universidad Democrática, Crítica y Popular”, en AGÜERA IBÁÑEZ, Enrique (coord.), El 68 en Puebla. Memoria y encuentros. Puebla, Benemérita Universidad Autónoma de Puebla.

MARTÍNEZ NATERAS, Arturo. (1972): Sery función social del Estudiante, Culiacán, Universidad Autónoma de Sinaloa.

ORNELAS, Carlos. (1994): De la crisis a la reconstrucción: el cambio institucional en la $B U A P$, México, ANUIES.

PANSTERS, Wil (coord). (1996): La mirada del Fénix. Universidad y sociedad en Puebla, 1880-1990, México. Centro de Estudios Universitarios-BUAP.

PANSTERS, Wil. (1998): Política y poder en Puebla. Formación y ocaso del cacicazgo avilacamachista, 1937-1987, México, Fondo de Cultura Económica.

RIUS FACIUS, Antonio. (1980): ¡Excomulgado! Trayectoria y pensamiento del Pbro. Dr. Joaquín Sáenz, Arriaga, México, Costa - Amic Eds.

SANTIAGO DIONISIO, Octaviano. (1981): ElMovimiento Estudiantil Guerrerense, Chilpancingo. Cuadernos de la FEUG.

SOTELO MENDOZA, Humberto. (1980): "El movimiento universitario popular en Puebla (1973-1983)", en Crítica. Revista de la UAP, Puebla. No. 19, s. f. (2004): 1972-1973, Puebla de los demonios. México, B UAP. 
THERÁN, Marta. (1980): "El levantamiento de los campesinos gasquistas". Cuadernos Agrarios, Editorial Macehual, Año V, No. 10-11.

VALLE, Eduardo. (1979): “El Movimiento Estudiantil", en 50 años de oposición en México, México, UNAM-FCPS.

VÉLEZ PLIEGO, Alfonso. (1978): “La sucesión rectoral, las lesiones de la historia y las tareas actuales del movimiento universitario democrático”, en Revista Crítica de la UAP, Año I, No. 1, oct-dic.

(1977): “La situación regional y la política de los comunistas", en Informe y resoluciones del I Congreso Regional Puebla-Tlaxcala, Puebla, Ediciones del Comité Regional del P.C.M.

VRIES, Wietse de (2001): El exorcismo de diablos y ángeles. Los efectos de las Políticas públicas sobre el trabajo académico. Aguascalientes, Universidad Autónoma de Aguascalientes.

VRIES, Wietse de. (2002) "Lunes por la mañana: la Universidad Autónoma de Puebla en visión comparativa”, en La transformación de la Universidad mexicana. Diez estudios de caso en transición. México, Universidad Autónoma de Zacatecas, Miguel Ángel Porrúa.

MORENO BOTELLO, Ricardo. (1996): "Historia de una crisis autónoma. La UAP de 1975 a 1990”, en la mirada del fénix. Puebla, Centro de Estudios Universitarios.

ZAMARRIPA, Florencio. (1964): Diaz Ordaz: Ideologiay perfil de un revolucionario, México, Editorial Futuro.

ZÚÑIGA, Francisco. (1972): "Puebla, once años de violencia", en Revista de Revistas, Núm. 12, 18/VIII.

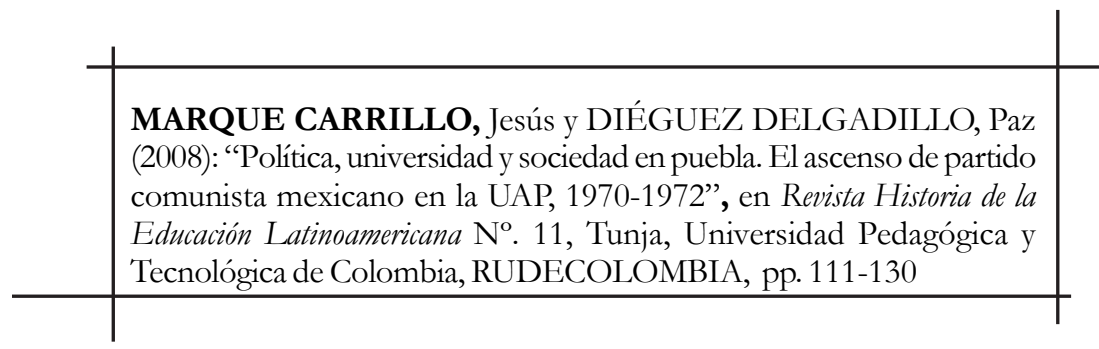

